\title{
FORMAR ACÓLITOS DA EDUCAÇÃO OU PRODUTORES DO CONHECIMENTO?
}

\author{
Prof. Dr. Sérgio Rogério Azevedo JUNQUEIRA*
}

\section{Resumo}

"O professor é aquele que de repente aprende", afirma Riobaldo no romance "Grande Sertão Veredas" de Guimarães Rosa, este é o desafio que coloco, ao refletir sobre a formação do docente, de maneira particular no Ensino Religioso, partindo do pressuposto que este profissional deve ser capacitado como todo e qualquer professor, já que será responsável por um dos componentes curriculares com uma intenção clara: a formação do cidadão que possui uma cultura e está inserido em contexto de rápidas e significativas transformações.

Palavras-chave: Capacitação docente - Ensino Religioso - Educação.

\section{Abstract}

"A teacher is one who suddenly leams", says Riobaldo in the novel "Grande Sertão Veredas" by Guimarães Rosa. This is the challenge I place on reflecting upon the teacher's schooling, specially in the Religious field. Based on the principle that the professional in such area schould be skilled as any ather teacher, and adminitting he will be responsible for one of the curricula components, there should be a clear objective: the upbringing of the citizen who is cultured and insert within a context of fast and meaningful transformations.

Key words: Teaching capacity - Religious education - Education.

* Mestre e Doutor em Ciências da Educação. Diretor Geral dos Cursos da Área de Educação da PUCPR. Professor Pesquisador do Programa de Pós-Graduação - Mestrado em Educação da PUCPR. Professor de Didática da PUCPR. Coordenador do Grupo de Pesquisa Educação e Religião da PUCPR. 


\section{Introdução}

A ideologia é um "corpus" de representações e de normas que fixam e determinam de antemão o que se deve e como se deve pensar, agir e sentir. Por sua anterioridade, a ideologia predetermina os atos de pensar, agir, querer ou sentir, de modo que os nega enquanto acontecimentos novos e temporais. Possui a finalidade de produzir uma universalidade imaginária da realidade. Contemporaneamente está montada sobre o "mito da racionalidade do real", entendida como razão inscrita nas próprias coisas e exprimindo-se por meio das idéias de organização e de planejamento. A racionalidade consiste pura e simplesmente em separar de modo radical aqueles que decidem ou dirigem, daqueles que executam ou são dirigidos, retirando destes últimos todo e qualquer poder sobre sua própria atividade ${ }^{1}$.

Neste contexto é que podemos compreender que a organização dos seres humanos é dinâmica e intensa, é utilizada para, ao longo da história, nas comunidades, justificarem transformações, desde as lentas e progressivas, até as rápidas e aparentemente desarticuladas, que popularmente são denominadas de "modismos", alterados conforme a época, mas dificilmente "ingênuas".

O que temos hoje é uma economia, impulsionada pela sociedade da informação, enraizada e guiada pelo desenvolvimento e expansão dessas informações e pelo entretenimento globalizado em formato eletrônico, computadorizado e digital, gerando inúmeros conhecimentos por meio de uma comunicação simbólica.

Conseqüentemente, essas alterações deram origem a uma nova cultura de aprendizagem, formas de se confrontar o conhecimento de modo profundo e significativamente diferente, os quais podemos caracterizar em três passos: a explosão da informação, a multiplicação e a diversificação das formas de saber e conhecer, exigindo uma educação contínua e permanente.

A evolução do conhecimento ao longo da história moderna construiu-se estilhaçando o global, a compartimentando os saberes, e carregou muito longe o desenvolvimento especializado, fragmentou o conhecimento em múltiplas disciplinas, as quais, pouco a pouco, foram se separando e não mais se reconhecendo ${ }^{2}$.

A nova cultura da aprendizagem se reflete na cultura educacional das instituições escolares, por meio de suas metas e métodos, expressos nas formas de organizar o trabalho dos alunos em sala de aula, assim como as relações entre docentes e discentes, o que significa a exigência de uma verdadeira mudança na cultura escolar atual. O que encontramos nesse ambiente muitas vezes é a compreensão de que tudo mude, mas que continue igual ${ }^{3}$.

A modernidade é caracterizada por uma ruptura com a tradição, propondo, no sujeito pensante, a busca de um novo ponto de partida alternativo, mesmo porque na sociedade marcada hoje pela informação o caminho é a 
produção do conhecimento, em uma visão globalizadora, progressista, com a superação de metodologias reprodutivas e conservadoras.

Em suma: é necessário mudar, mas isso não ocorre, porque ousar é sair do comodismo.

O conhecimento é enfocado com base na localização histórica de sua produção e entendendo-o como provisório e relativo, valorizando a ação reflexiva; e a disciplina, tomada como capacidade de estudar, refletir e sistematizar, privilegiando a intervenção para novas conquistas. Para tal, estimulam-se a análise e a capacidade de compor e recompor dados, informações, argumentos, idéias, a fim de valorizar a ação e a reflexão crítica, a curiosidade, a inquietação e a incerteza. Estas são consideradas características do sujeito cognoscente, favorecendo o pensamento divergente, visto que o pensamento é assumido como interdisciplinar, atribuindo significados próprios aos conteúdos, em conformidade com os objetivos acadêmicos.

Um dos resultados é que a revolução tecnológica em curso é irreversível nos seus aspectos básicos, inclusive no manejo econômico-político no qual está inserida atualmente. Desta forma, o advento da civilização, centrada na comunicação potencializa esses recursos tecnológicos, renovados com uma rapidez incrível, desviando a cultura, até há pouco centrada na verticalidade das trocas sociais, para a exploração da horizontalidade ${ }^{4}$.

\section{A compreensão e a pluralidade na e da educação}

A educação, como um fenômeno social e universal, é compreendida de vánias formas e significados por meio dos tempos, de acordo com seus objetivos e funções, cooperando na manutenção ou busca de uma transformação nas comunidades.

Ela é desenvolvida mediante das diferentes relações sociais, políticas e econômicas em uma determinada sociedade. A educação é, portanto, um processo de desenvolvimento unilateral da personalidade, envolvendo a formação de qualidades humanas, físicas, morais, intelectuais, estéticas, tendo em vista a orientação da atividade humana em sua relação com o meio social, em um determinado contexto.

No seio da educação, encontra-se o processo de ensino-aprendizagem, que para muitos é qualificado por uma ação pedagógica embasada em um sólido domínio do conhecimento, de uma metodologia necessária ao seu desdobramento e avaliações que verifiquem a reprodução das informações transmitidas ${ }^{5}$. Outra forma de compreender é a aprendizagem concebida como uma construção individual e social dos sujeitos, podendo ser o resultado de ações realizadas em um contexto e manifestadas em representações coletivas evidenciadas pela efetivação das avaliações, demonstrando uma nova utilização destas mesmas informações. 
O que significa que o conhecimento emergente não é uma simples rearticulação do sistema, nem a introdução do novo no já instituído, como propõem as concepções conservadoras, cuja prática é pensada do centro para a periferia, buscando uma inserção acrítica do novo no velho. Nesse sentido, a inovação pode servir para perpetuação do "status quo", a inovação é de fato uma significativa ruptura do sistema ${ }^{6}$.

Dentre as diferenciações explícitas, destacam-se as abordagens de avaliação e mensuração. Enquanto avaliação se refere ao mérito do processo, a mensuração indica o status de um fenômeno. Uma diferença entre critérios de produtos e de processo. Existe uma distinção entre a avaliação feita durante o processo educacional e a realizada após esse processo, pois os papéis são diferentes. Enquanto a avaliação produzida durante o processo tem a finalidade de aperfeiçoar o ensino (formativo), a produzida ao final é para emitir um parecer e tomada de posição (somativa).

Para muitos, a educação ficou reduzida a elaboração de paradigmas, que, segundo $\mathrm{KUHN}^{7}$ (1991), é um instrumento significativo que nos orienta, permite avançar, assim como impede de perceber aspectos que não favoreçam plenamente o ser humano. Estes são padrões, modelos que agem como filtros, retendo os dados que chegam à mente. Quando esses dados concordam com nossos referenciais, têm acesso fácil ao reconhecimento, quando não, sequer percebemos o elemento que é apresentado. Enquanto para Capra (1988), ampliando este conceito, um paradigma "significaria a totalidade de pensamentos, percepções e valores que formam uma determinada visão de realidade, é a base do modo como uma sociedade se organiza". Um paradigma, pois, seria apenas um referencial de análise e interpretação de uma realidade. Uma construção teórica que tem o sentido de auxiliar a organização das relações sociais, em termos de tempo e espaço.

Na realidade, a educação não é uma justaposição de modelos, mas uma mescla de elementos articulados e porque não dizer aglutinados segundo diversas variáveis, especialmente a cultura das comunidades. Assim, o papel da natureza, que é humanizadora, obriga o ser humano a se mudar, transformar-se, na medida em que ele mesmo a altera, na desafiadora relação homemnatureza e homem-homem são construídos os objetivos e intenções das diferentes propostas de educação, operacionalizadas também nas instituições escolares.

Toda essa divergência na elaboração de propostas educativas é conseqüência de uma ciência que exige uma nova visão de mundo, globalizada e não tão fragmentada, sobretudo dinâmica e necessariamente articulada ou seqüencial ${ }^{8}$. 


\section{Professor e sua formação}

É difícil ser um docente em um país em construção, desafiado pela comunidade intemacional, que exige que se equipare a padrões que necessariamente não contemplam a cultura e a tradição do povo, expressos, por exemplo, por meio da escolha de componentes curriculares que nada significam na formação dos e para os alunos ${ }^{9}$.

A tarefa do professor neste momento é a de saber articular uma metodologia de ensino que se caracterize por uma variedade de ações que favoreçam a criatividade dos alunos, de forma consciente e comprometida com a totalidade do processo educativo transformador.

Significa dizer que a experiência inovadora pressupõe uma relação dinâmica entre a teoria e a prática, para além de uma simples relação de aplicação à qual esta última parece destinada na rotina cumicular ou das aulas. É por isso que, em oposição à repetição, identificamos a inovação, com a práxis inventiva: incluindo a produção de algo novo no sujeito do aprendizado, por meio da resolução intencional de um problema, que pode ser tanto de índole prática como puramente teórica. A inovação está entrelaçada com formação docente. Formar é objetivar-se e subjetivar-se em um movimento dialético que vai além, sempre mais longe. A formação é a construção do próprio caminho de desenvolvimento profissional e integral, uma trajetónia pessoal, por meio da busca em si mesmo e nos outros. ${ }^{10}$

Portanto, ao considerar o cotidiano do professor na educação básica, torna-se necessária uma formação orientada, com uma atenção ao espaço da escola, em que o docente desenvolverá o seu pensar e fazer pedagógico, ultrapassando a pura reprodução de conhecimentos e valores acumulados pelas gerações ao longo da história das comunidades.

O professor, ao agir segundo uma abordagem integrada, configurada por uma compreensão da produção do conhecimento, em vista da autonomia do aluno, necessitará de um processo formador que lhe permita ser mais do que um mediador, mas um investigador, com habilidades para aprender a observar, formular questões, levantar hipóteses, selecionar dados e instrumentos que permitam expressar seus achados e dúvidas. Contribuir na capacitação de docentes problematizadores é um exercício para a educação superior.

A Lei de Diretrizes e Bases da Educação brasileira, em seu artigo 13, apresenta algumas das tarefas do professor como: participar da elaboração da proposta pedagógica do estabelecimento de ensino; elaborar e cumprir o plano de trabalho, segundo a proposta pedagógica da instituição; zelar pela aprendizagem dos alunos; estabelecer estratégias de recuperação para os alunos de menor rendimento; ministrar os dias letivos e horas-aula estabelecidos, além de participar integralmente dos períodos dedicados ao planejamento à avaliação e ao desenvolvimento; colaborar com as atividades de articulação da escola com as famílias e a comunidade. 
Para tal, apontamos algumas características do professor que possa responder ao perfil LDB: estar em constante movimento, atento ao seu contexto e conseqüentemente aos dos alunos, ser instigador, promovendo múltiplas tensões para o estudante, estar preocupado com a auto-atividade dos mesmos e com o atendimento às suas necessidades indivualizadas e propiciar atividades coletivas que estimulem a interação entre todos os que estão em classe.

Entretanto, os responsáveis por tal capacitação necessitam aprender ensinar de um modo que eles mesmos não foram ensinados; desenvolver e aplicar estratégias de sala de aula que enfatizem as novas metas de aprendizado profundo requeridas por um analista simbólico; sejam capazes e obrigados a se comprometerem com seu próprio aprendizado, muito além do ponto de qualificação inicial; possam trabalhar eficazmente e estejam ávidos por aprender com outros professores, em suas próprias escolas e em outros lugares; considerem a pesquisa e os estudos no ensino e aprendizagem como vitais para o aperfeiçoamento; considerem a diferença, o conflito e o debate como uma oportunidade para aprofundar o coleguismo e não como uma ameaça; vejam os alunos como parceiros, não apenas como objetos da aprendizagem e do aperfeiçoamento; vejam os pais e as comunidades como fontes de aprendizagem e não apenas como amontoados de problemas e deficiências. Ao se tornarem agentes de sua própria mudança, tornam-se também qualificados a reagirem rápida e eficazmente às mudanças sociais e educacionais constantes que ocorrem à sua volta ${ }^{11}$.

Levando-se em consideração, pois, todo o exposto, chega-se à conclusão de que o espaço da educação ${ }^{12}$ superior deve procurar favorecer a formação de pessoas qualificadas e co-responsáveis pelo desenvolvimento das comunidades em que está inserida. De maneira especial, a recente história, devido ao escopo e ritmo das transformações, tem solicitado respostas inéditas a antigas e novas questões.

Para alcançar estas metas, pode ser necessária a reforma de currículos, com a utilização de novos e apropriados métodos que permitam ir além do domínio cognitivo das disciplinas. Novas aproximações didáticas e pedagógicas devem ser acessíveis e promovidas, a fim de facilitar aquisição de conhecimentos práticos, competências e habilidades para a comunicação, análise criativa e crítica, a reflexão independente e o trabalho em equipe em contextos multiculturais, cuja criatividade também envolva a combinação entre 0 saber tradicional ou local e o conhecimento aplicado da ciência avançada e da tecnologia. Esses currículos reformados devem levar em conta a questão do gênero e o contexto cultural, histórico e econômico específico de cada país, 0 ensino das normas referentes aos direitos humanos e educação sobre as necessidades das comunidades em todas as partes do mundo, tudo incorporado nos diversos componentes curriculares. 
A organização da formação docente, em cursos organizados em Instituições de Educação Superior, visa a contribuir para compreensão, interpretação, preservação, reforço, fomento e difusão das culturais nacionais e regionais, em cuja teoria e prática interagem ${ }^{13}$.

Nessa perspectiva, o papel, sobretudo das Universidades, é o de formular intelectualmente a experiência humana, sempre renovada, para que se torne consciente e progressiva, preocupada em cultivar a imaginação e dar sentido e significado às coisas, já que a vida humana é uma sublime inquietação do conhecer e do fazer ${ }^{14}$.

Tal concepção do espaço em que ocorre a formação docente não é nova, foi proposta no século XIX por Humboldt, possibilitando que a educação prepare o ser humano para descobrir a ciência, para formular a ciência a ser socializada em outras etapas da formação do cidadão ${ }^{15}$.

A formação docente, desenvolvida na educação superior, será diferenciada pela dimensão do papel da pesquisa e de sua articulação com 0 ensino desenvolvido na capacitação do futuro professor, sobretudo se o ensino for compreendido como formação para a reflexão crítica daquilo que faz, redimensionando atitudes dos futuros professores em ambientes pluralistas e sensíveis à resignificação permanente na e da sociedade ${ }^{16}$.

Tal concepção será percebida a partir da organização curricular desenvolvida nos diferentes cursos de capacitação, que saibam responder às questões: Como ensinar? Para quem? Como fazê-lo? O que ensinar? Para que ensinar ${ }^{17}$ ?

O trabalho de educar deve se apoiar em certas concepções sobre aprendizagem e ensino, produtos de uma cultura educacional, em que professores e alunos foram formados. Por meio de sua prática cotidiana nas instituições. Essas concepp̧ões constituíram verdadeiras teorias implícitas sobre a aprendizagem e o ensino, profundamente enraizados, não apenas na cultura escolar dominada por atividades, mas também na organização social da classe, na avaliação.

Boa parte dos pressupostos da cultura tradicional entra em choque com as exigências das novas e necessárias propostas educacionais, fundamentais para enfrentar as mudanças em andamento, as quais, vagamente, podem ser identificadas sob o rótulo de um "ensino construtivista". Também será necessário promover mudanças nas teorias implícitas dos docentes, se desejarmos conseguir que eles atuem como agentes de um processo educacional que responda aos novos tempos ${ }^{18}$.

Para tal, existe a educação superior com a tarefa social de educar e formar pessoas altamente qualificadas, cidadãs e cidadãos responsáveis capazes de atender às necessidades em todos os aspectos da atividade humana, oferecendo-lhes qualificações relevantes, conhecimento teórico e prático de alto nível, mediante cursos e programas. 
Vale lembrar que a Universidade não é o único e exclusivo espaço para a difusão dos conhecimentos, como recorda Anísio Teixeira, pois não se trata de apenas conservar a experiência humana, mas de favorecer uma formação qualificada e gerar a pesquisa que desenvolva a produção do conhecimento. A universidade é, em essência, a reunião entre os que sabem e os que desejam aprender. Há toda uma iniciação a se fazer, por meio de um cultivo da imaginação, ou seja, dar sentido e significado às coisas. A vida humana não é o transcorrer monótono de uma rotina quotidiana, a vida humana é, sobretudo, a sublime inquietação de conhecer e de fazer.

A universidade será, assim, um centro de saber, destinada a aumentar o conhecimento humano, um noviciado de cultura capaz de alargar a mente e amadurecer a imaginação dos jovens para a aventura do conhecimento, uma escola de formação de profissionais e o instrumento mais amplo e mais profundo de elaboração e transmissão da cultura comum brasileira. Estas são as ambições da universidade moderna e profundamente nacional, mas intimamente ligada, por esse amplo conceito de suas finalidades, às universidades de todo o mundo, à grande fraternidade internacional do conhecimento e do saber $^{19}$.

A universidade, enquanto esforço educativo, é o "locus" da cultura nacional e de sua socialização. $\mathrm{O}$ grande objetivo da educação é de formar a consciência nacional ${ }^{20}$.

Tradicionalmente, são três os papéis específicos atribuídos à Universidade: ensino de nível superior, pesquisa científica e serviço à comunidade. Mas esses papéis podem ser próprios também de outras instituições similares. O elemento específico que distingue a Universidade das demais instituições é a problemática dos critérios fundamentais, quer dizer, o questionar sistematicamente os pressupostos, os conceitos fundamentais, os métodos, os graus de legitimidade, os limites das diferentes disciplinas e, enfim, as condições de existência da própria ciência.

Talvez não haja instituição tão paradoxal quanto à universidade revolucionária, por vocação, dos fins e propósitos que caracterizam o "ethos" inquietante de sua busca de novos conhecimentos, já que ela é, ao mesmo tempo, conservadora, pela memória intelectual dos conhecimentos passados e pela vigorosa permanência ao longo dos séculos ${ }^{21}$.

Formar alunos na universidade não significa ensinar o que já se encontra escrito nos livros, ou seja, não se trata apenas de propiciar ao aluno, por meio dos estudos, uma cultura humanística; pretende-se, com a aprendizagem, mostrar o processo de como chegar ao conhecimento.

A universidade deve provocar novas decisões curriculares, implicando falar sobre qual e que conhecimento ensinar, para quem, como e para que fazê-lo. Essa decisão, aparentemente simples, implicam seu âmago todo um intrincado emaranhado de relações que envolvem distribuição de poder e 
controle social, aspectos esses nem sempre visíveis, quando se escolhem itens do binômio planejamento-avaliação para uma organização cotidiana de atividades de uma disciplina.

Somente por meio da pesquisa será possível repensar a atuação da universidade, do que ela propõe, pois não existe o caminho, mas caminhos, uma pluralidade deles e desconhecidos. Contudo, é necessário escolher algum, e escolher é sempre um risco. Nada nos assegura o resultado do caminho escolhido, ainda que só parcialmente.

\section{Acólito e o produtor}

Os professores que atuam nas diferentes áreas do conhecimento comportam-se como acólitos ${ }^{22}$, ou seja, indivíduos que auxiliam no rito, seguindo orientações pré-determinadas para execução das ações ${ }^{23}$, ousando comparar o cotidiano universitário como uma representação ritualística em que o encontro pedagógico-relgioso entre docentes e discentes ocorre pela veiculação, transmitindo ideologias sociais e culturais ${ }^{24}$.

O cotidiano da sala de aula, espaço privilegiado deste ritual, não é uma unidade pura ou desencarnada, muito menos homogênea, ao contrário, é conflitante e provocadora, impregnada de "competições" oriundas da história dos que dela participam. Todos os elementos da comunidade escolar assumem a necessidade de manter este ritual, mesmo muitas vezes esquecendo a origem do mesmo e, sobretudo, a causa de sua organização, apenas resta a necessidade de iniciar todos aqueles que por algum motivo passam a fazer parte desse corpo.

O processo de ensino-aprendizagem, que ocorre em muitos espaços universitários, é o resultado de diferentes concepções: epistemológica, técnica, histórica e cultural, privilegiando aspectos da educação, ora o metodológico, ora o conteúdo, ou outro elemento de interesse sócio-político, transformando todos em "acólitos" de um "rito", que há muito perdeu sua justificativa. "Estático" é a tônica, quando deveria haver o "dinâmico".

As abordagens aqui propostas estão vinculadas a uma mesma concepção: a newtoniana-cartesiana, em que se privilegia a visão da necessidade de fragmentar o conhecimento e compreendê-lo como um mecanismo único. Estas categorias tornaram-se dominantes e fundamentais para a inelegibilidade de todos os membros deste processo, toda e qualquer divergência é de alguma forma repelida ${ }^{25}$.

Diferentemente do acólito, o produtor do conhecimento assume a proposta de uma nova cidadania, pressupondo a revisão das relações de poder em todos os âmbitos da sociedade, no sentido de reinventar o poder, proporcionando, assim, à reinvenção social. A constituição de uma nova sub- 
jetividade, aberta, dinâmica e flexível no processo de tornar-se de direito e de fato cidadão, busca ao revisar o papel do conhecimento e da informação em nossa sociedade ${ }^{26}$, difundindo uma cultura política e substancialmente democrática.

\section{Professor de ensino religioso}

Neste contexto encontra-se a problemática da Capacitação Docente para o Ensino Religioso, que, ao longo da história, tem sido responsável por complexas e intrincadas batalhas, nos quais concidadãos destrõem-se em nome, ou pelo uso de suas concepções religiosas.

Com esta perspectiva, o Fórum Nacional Permanente do Ensino Religioso insiste que: "O Ensino Religioso é direito de todo cidadão ${ }^{27}$ ".

O pluralismo religioso e étnico é um dos maiores tesouros do Brasil. É inadmissível que algumas crianças brasileiras, por professarem um credo que não o da maioria, sejam criadas na incômoda posição de serem vistas - e se vêem a si mesmas - como estrangeiras em sua própria pátria. Para ser autenticamente democrática, uma nação não pode se limitar a atender aos interesses da maioria. É preciso, igualmente, respeitar os direitos da minoria ${ }^{28}$. Portanto, em um país plural como este, em que a luta contra a discriminação e o preconceito é condição essencial para à construção de uma grande nação efetivamente democrática, talvez convenha, antes de mais nada, lidar com os preconceitos que ainda afetam boa parte da população em vez de, com a melhor das intenções, criar condições para acirrar os divisores já existentes no próprio lugar em que melhor deveriam ser combatidos, ou seja, na escola ${ }^{29}$.

Este é um grande desafio que o professor do Ensino Religioso encontra ao assumir este componente, sobretudo os que o formam. Para compreender todo esse movimento de escolarização, é importante ter claro que atualmente o conceito de "currículo", por sua vez, envolve outros três: currículo formal (planos e propostas pedagógicas), currículo em ação (aquilo que efetivamente acontece nas salas de aula e nas escolas), currículo oculto (o não dito, aquilo que tanto alunos, quanto professores trazem, carregado de sentidos próprios, criando formas de relacionamento, poder e convivência nas salas de aula). A base nacional comum refere-se ao conjunto de conteúdos mínimos das áreas de conhecimento articulados aos aspectos da vida cidadã ${ }^{30}$, por ser dimensão obrigatória dos currículos nacionais das áreas de conhecimento: referem-se às noções e conceitos essências sobre fenômenos, processo, sistemas e operações, que contribuem para a constituição de saberes, conhecimentos, valores e práticas sociais indispensáveis ao exercício a uma vida de cidadania plena.

Já para a instituição de uma base nacional comum, a partir da $\mathrm{LDB}$, 0 
currículo assume uma parte diversificada, supondo um novo paradigma curricular que articula a "Educação Fundamental" com a vida cidadã ${ }^{31}$.

Esta nova concepção é o resultado de um longo percurso na organização de disciplina, currículo e articulação dos elementos do processo de ensino aprendizagem para compreender a elaboração do Ensino Religioso. Como componente curricular, é necessário considerar esta estruturação e suas diretrizes.

A partir destes pressupostos, o modelo proposto para o Ensino Religioso, como resultado de todo este esforço, é o FENOMENOLÓGICO, estabelecido recentemente no momento em que a nação se confrontava com as conseqüências políticas de uma economia neoliberal, um subjetivismo cultural e uma concepção religiosa pentecostal carismática.

Conseqüentemente, a elaboração do texto para esta disciplina, presente na Lei de Diretrizes e Bases, responsável por explicitar elementos da Constituição (art. 210) ${ }^{32}$, foi desafiador e mobilizador, com inúmeras discussões.

O conceito de cidadania está em evolução, suas diversas dimensões assumem relevâncias diversificadas no correr do tempo, em decorrência do desenvolvimento da formação histórica. Cada corrente filosófica a percebe segundo seu ângulo de visão; entretanto, o direito à educação, como exercício à cidadania, parece indiscutível, pois constitui um instrumento de atuação social, possibilitando a leitura de seu contexto ${ }^{33}$.

Entre as características da formação do cidadão está a possibilidade de cada um expressar-se livremente, podendo apresentar suas idéias em todos os campos. Uma das conseqüências desta liberdade é a mudança de referencial, ou seja, de uma sociedade homogênea para a convivência com o pluralismo sócio-cultural-religioso.

A formatação estrutural do novo modelo foi organizada a partir das orientações do Conselho Nacional de Educação (CNE) para estruturação das "diretrizes curriculares", implicando a definição de um objeto e objetivos do componente curricular, o Ensino Religioso; optou-se pelo fenômeno religioso, pois para desenvolver a compreensão como disciplina escolar deveria considerar duas áreas em conjunto que este componente está envolvido: EDUCAÇÃO-ENSINO (escola) e RELIGIÃO (religiosidade), sendo que cada uma destas é, na verdade, uma constelação de aspectos na formação deste componente curricular.

O profissional que opta por este componente necessita de uma ampla formação para lidar com elementos profundamente intrincados. Para tanto, os objetivos propostos para esta licenciatura são:

- proporcionar o conhecimento dos elementos que compõem o fenômeno religioso, a partir das experiências religiosas percebidas do contexto do educando;

- ser capaz de subsidiar o educando na formulação do questio- 
namento existencial, em profundidade, e na resposta com a devida informação;

- analisar o papel das tradições religiosas na estruturação e manutenção das diferentes culturas e manifestações sócioculturais;

- facilitar a compreensão do significado das afirmações e verdade de fé nas tradições religiosas;

- refletir o sentido da atitude moral como conseqüência do fenômeno religioso e expressão da consciência e da resposta pessoal e comunitária do ser humano;

- possibilitar esclarecimentos sobre o direito à diferença na construção de estruturas religiosas que têm na liberdade o seu valor inalienável (Cf. PCNER).

Com isso, poder-se-á desenvolver uma prática pedagógica isenta de proselitismo; assegurando o respeito à diversidade de cultura, religiosa do Brasil de acordo com a LDB 9394/96, Artigo 13, usando de sensibilidade, discernimento e equilíbrio nas relações com o fenômeno religioso e suas diferentes manifestações (Cf. FONAPER. 1998. Capacitação Docente. Brasília: UCB, 14.).

Habilitar o profissional do Ensino Religioso, hoje, significa favorecer abertura para um novo espaço formativo que permita uma construção docente dinâmica, com qualidade de elaborador de idéias e não um mero copista.

\section{Notas bibliográficas}

1 Cf. CHAUÍ, M. 1979. Ideologia e Educação. São Paulo: Unicamp/ Mimeo. 34-35.

2 Cf. SOBRINHO, J. 2000. Avaliação da Educação Superior. Petrópolis: Vozes, 36.

3 Cf. POZO, J. - ECHEVERRÍA, M. As concepções dos professores sobre a aprendizagem. In: "Pátio" 16(2001)4, 19.

4 Cf. SOBRINHO, J. 2000. Avaliação da Educação Superior. Petrópolis: Vozes, 24.

5 Cf. CUNHA, M. -LEITE, D. 1996. Decisões Pedagógicas e estruturas de poder na Universidade. Campinas: Papirus, 13.

6 Cf. CASTANHO, M (Org.). 2000. O que há de novo na educação superior, do projeto pedagógico à prática transformadora. Campinas: Papirus, 89-111.

7 Nota: Para Thomas Kuhn o paradigma é a constelação de crenças, valores e técnicas partilhadas pelos membros de uma comunidade $(1994,225)$, refere-se ao modelo, padrão, compartilhados que permitem a explicação de certos aspectos da realidade.

8 Cf. UNESCO. 1998. Declaração Mundial sobre Educação Superior no século XXI: visão e ação. Piracicaba: UNIMEP, art. 5. 
9 Cf. GHIRALDELL, P. 2000 2. ed. História da Educação. São Paulo: Cortez, 26-27.

10 Cf. CASTANHO, M (Org.). 2000. O que há de novo na educação superior, do projeto pedagógico à prática transformadora. Campinas: Papirus, 64-65; 96.

11 Cf. HARGREAVES, A. O Ensino como profissão paradoxal. In: "Pátio” 4(2001)16, 16.

12 Nota: "A educação superior compreende todo tipo de estudos, treinamento ou formação para pesquisa em nível de pós-secundánio, oferecido por universidades ou outros estabelecimentos educacionais aprovados como instituições de educação superior pelas autoridades competentes do Estado". Definição aprovada pela Conferência Geral da UNESCO em sua 27 a reunião (novembro de 1993), na recomendação sobre a convalidação dos estudos, títulos e diplomas de educação superior.

13 Cf. UNESCO. 1998. Declaração Mundial sobre Educação Superior no século XXI: visão e ação. Piracicaba: UNIMEP, art. 01.

14 Cf. TEIXEIRA, A. 1998. Educação e universidade. Rio de Janeiro: UERJ, 35 ss.

15 Cf. TEIXEIRA, A. 1998. Educação e universidade. Rio de Janeiro: UERJ, 107-108.

16 Cf. CASTANHO, M. (Org.). 2000. O que há de novo na educação superior, do projeto pedagógico à prática transformadora. Campinas: Papirus, 80.

17 Cf. LAMPERT, E. 1999. Universidade, docência e globalização. Porto Alegre: Sulina, 58.

18 Cf. POZO, J. - ECHEVERRÍA, M. As concepções dos professores sobre a aprendizagem. In: "Pátio" 16(2001)4, 19.

19 Cf. A. TEIXEIRA. 1998. Educação e universidade. Rio de Janeiro: UERJ, 169.

20 Cf. A. TEIXEIRA. 1998. Educação e universidade. Rio de Janeiro: UERJ, 98.

21 Cf. L. CHERMANN. 1999. Cooperação internacional e Universidade. Uma nova cultura no contexto da globalização. São Paulo: EDUC, 9.

22 Nota: O acolitato foi instituído para ajudar o diácono e ao sacerdote. Seu trabalho é servir ao altar nas ações litúrgicas, em alguns casos poderá atuar como ministro extraordinário da eucaristia. A este cabe dominar todas as informações referentes ao culto (GÉLINEAU, J. 1991. Assemblea Santa. Manuale di liturgia pastorale. Bologana: Edizioni Dehoniane, 304.)

23 Cf. SCHLESINGER, H. - PORTO, H. 1995. Dicionário Enciclopédico das Religiões, Vol. I. Petrópolis: Vozes, 52.

24 Cf. MACLAREN, P. 1992. Rituais na escola. Em direção a uma economia política de símbolos e gestos na educação. Petrópolis: Vozes, 29-33.

25 Cf. MORIN, E. - MOIGNE, J. 2000. A inteligência da complexidade. São Paulo: Peirópolis, 101.

26 Cf. LAMPERT, E. 1999. Universidade, docência e globalização. Porto Alegre: Sulina.122.

27 Nota: Campanha de divulgação da nova concepção do Ensino Religioso, realizada em 1998 pelo FONAPER.

28 Cf. H. SOBEL. Religião e escola pública. In: “Jornal APEOESP” (1995), 5.

29 Cf. I. LEVIN. Educação Religiosa. In: "Folha de São Paulo" (3 set. 1995), Cad. Opinião.

30 Nota: "[...] art. 26 Os currículos do ensino fundamental e médio devem ter uma base nacional comum, a ser complementada em cada sistema de ensino e estabelecimento escolar, por uma parte diversificada, exigida pelas características regionais e locais da sociedade, da cultura, da economia e da clientela 
[...]”. (MINISTÉRIO DA EDUCAÇÃO E DESPORTO, Lei de Diretrizes e Bases da Educação Nacional - Lei n. 9.394/96. Rio de Janeiro: Qualitymark, 1997, art. 26.)

31 Nota: “[...] O significado que atribuímos à Vida Cidadã é o exercício de direitos e deveres de pessoa, grupos e instituições na sociedade que me sinergia, em movimentos cheio de energias que se trocam e se articulam, influem sobre múltiplos aspectos, podendo assim viver bem e transformar a convivência apara melhor [...]”. (CONSELHO NACIONAL DE EDUCAÇÃO. Parecer sobre Diretrizes Curriculares (Parecer 4 - 29 janeiro 1998). Brasília, Mimeo., 1998.)

32 Nota: “[...] art. 210 Serão fixados conteúdos mínimos para o Educação Básica de maneira a assegurar formação básica comum e respeito aos valores culturais e artísticos, nacionais e regionais. $§ 10$ ensino religioso, de matrícula facultativa, constituíra disciplina dos horários normais das escola públicas de Educação Básica [...]". (REPÚBLICA FEDERATIVA DO BRASIL, Constituição da República Federativa do Brasil (5 outubro 1988). In: P. BONAVIDES - R. AMARAL Textos Políticos da História do Brasil Vol. IX, Brasília, Senado Federal, 1996.)

33 Cf. P. SINGER. 1999. O Brasil na crise, perigos e oportunidades São Paulo. Contexto, 74-76.

\section{Referências Bibliográficas}

ANDRADE, R. 1990. A questão dos paradigmas, Belo Horizonte: Mimeo.

ANDRÉ, M. - OLIVEIRA, M. (Orgs.). 1997. Alternativas do ensino de didática. Campinas: Papirus.

ARANHA, M. 1989. História da educação. São Paulo: Moderna.

ARTACHO, $R$. Nuevas claves para la formación permanente del profesor. In: "Religión y Escuela" 148(2001)XVIII, 40-41.

ASSMANN, H. 1998. Reencantar a educação, Petrópolis: Vozes.

BEHRENS, M. 1999. O paradigma emergente e a prática pedagógica. Curitiba: Champagnat.

BERBEL, N. (Org.). 1998. Metodologia da problematização. Experiências com questões do ensino superior, ensino médico e clínico. Londrina: UEL

BERBEL, N. (Org.). 1998. Questões de Ensino na Universidade. Conversas com quem gosta de aprender para ensinar. Londrina: UEL.

BRANDÃO, Z. (Org.). 1999 5a. Edç. A crise dos paradigmas e educação. São Paulo: Cortez.

BUARQUE, C. 1994. A aventura da Universidade. São Paulo: ÙNESP/ Rio de Janeiro: Paz e Terra.

CASTANHO, M. (Org.). 2000. O que há de novo na educação superior, do projeto pedagógico à prática transformadora. Campinas: Papirus. 
CHAUÍ. M. 1979. Ideologia e Educação. São Paulo: Unicamp/ Mimeo.

CHERMANN, L 1999. Cooperação internacional e Universidade. Uma nova cultura no contex to da globalização. São Paulo: EDUC.

COSTA - I. SILVA, C. Razão comunicativa: uma construção possível? In: "Revista de Educação da AEC" 28(1999)112, 23 - 31.

COSTA, R A seleção de conteúdos ideológicos, políticos e didáticos. In: “Educação e Realidade" 1(1992)17, 65 - 68.

CUNHA, M. - LEITE, D. 1996. Decisões Pedagógicas e estruturas de poder na Universidade. Campinas: Papirus.

DORNELES, B. Uma perspectiva histórica da aprendizagem. In: "Pátio" 4(2001)16, 29.-33.

DURKHEIM, E. 1995. A evolução pedagógica. Porto Alegre: Artes Médicas.

EINSTEIN, A. 1981, 17a. Ed. Como vejo o mundo, Rio de Janeiro: Nova Fronteira.

FICHTE, J. 1999. Por uma universidade orgânica. Rio de Janeiro: UERJ.

FONAPER. 1998. Capacitação Docente. Brasília: UCB

FREIRE, P. 1987 13a. Edç Educação e mudança, São Paulo: Paz e Terra.

GADOTTI, M. 1991 ta edç. Pensamento pedagógico brasileiro. São Paulo: Ática.

GADOTTI, M. 1993. Histórias das idéias pedagógicas. São Paulo: Ática.

GÉLINEAU, J. 1991. Assemblea Santa. Manuale di liturgia pastorale. Bologna: Edizioni Dehoniane.

GHIRALDELU, P. 2000 2a edç. História da Educação. São Paulo: Cortez.

GUARNIERI, M. (Org.). 2000. Aprendendo a Ensinar, o caminho nada suave da docência. Campinas: Autores Associados.

HARGREAVES, A. O Ensino como profissão paradoxal. In: "Pátio" 4(2001)16, 13-18.

HORGAN, J. 1998. O fim das ciências. Uma discussão sobre os limites do conhecimento científico, São Paulo: Companhia das Letras.

JUNQUEIRA, S. Ensino Religioso - uma real mudança de paradigmas. In: "Diálogo" 3(1998)11, 5 - 9.

KOURGANOFF, W. 1990. A face oculta da Universidade. São Paulo: UNESP.

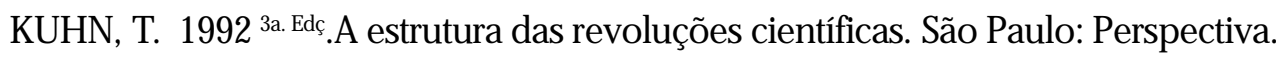


LAMPERT, E. (Org.). 2000. A universidade na virada do século 21. Porto Alegre: Sulina.

LAMPERT, E. 1999. Universidade, docência e globalização. Porto Alegre: Sulina.

LARA, T. Visões de mundo. In: "Revista de Educação da AEC" 25(1996)98, 24 31.

LBÂANEO, J. 1990. Didática. São Paulo: Cortez.

LIMA, E. Questões atuais sobre o desenvolvimento humano. In: "Pátio" 4(2001)16, 24-28.

LUKESI, C. 1990. Filosofia da Educação. São Paulo: Cortez.

MACLAREN, P. 1992. Rituais na escola. Em direção a uma economia política de símbolos e gestos na educação. Petrópolis: Vozes.

MARTINS, P. 1998. A didática e as contradições da prática. Campinas: Papirus. MATTOS, L 1973 11a. edç. Sumário de didática geral. Rio de Janeiro: Aurora. MIZUKAMI, M. 1986. Ensino: as abordagens do processo. São Paulo: EPU. MONROE, P. 1987. História da educação. São Paulo: Nacional.

MORAES, M. 1997. O paradigma educacional emergente, Campinas: Papirus. MORAES, M. O paradigma educacional emergente: implicações na formação do professor e nas práticas pedagógicas. In: "Em Aberto" 16(1996)70, 57 - 68.

MOREIRA, M. 1999. Aprendizagem significativa. Brasília: UNB.

OLIVIERA, M. (Org.). 1993. Didática: ruptura, compromisso e pesquisa. Campinas: Papirus.

PASSOS, I. (Org.). 1988. Repensando a didática. Campinas: Papirus.

PIAGET, J. 1988. Psicologia e Pedagogia. Rio de Janeiro: Forense.

PILETTI, C. - PILETTI, N. Filosofia e história da educação. São Paulo: Ática. POZO, J. - ECHEVERRÍA, M. As concepções dos professores sobre a aprendizagem. In: "Pátio" 4(2001)16, 19 - 23.

PROTA, L - HANSEN, G. 1998. A universidade em debate. Londrina: UEL REALE, G. - ANTISERI, D. 1983. II pensiero occidentale dalle origini ad oggi, Vol. III. Brescia: La Scuola. 
RIBEIRO, M. 1988 8a. Edç. História da educação brasileira. A organização escolar. São Paulo: Cortez.

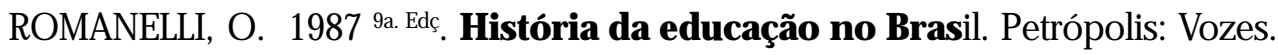

SANDRINI, M. Paradigmas de qualidade. In: "Revista de Educação da AEC" 23(1994)92, 25 - 39.

SANTOS, C. 1999. Educação escolar brasileira. São Paulo: Pioneira.

SCHLESINGER, H. - PORTO, H. 1995. Dicionário Enciclopédico das Religiões, Vol. I. Petrópolis: Vozes.

SCHWARTZMAN, S. - CASTRO, C. (Org.). 1986. Pesquisa Universitária em questão. Campinas: Ícone

SILVA, C. 1999. Curso de pedagogia no Brasil. História e identidade. Campinas: Autores Associados.

SOBRINHO, J. 2000. Avaliação da Educação Superior. Petrópolis: Vozes.

STRECK, D. 1994. Correntes pedagógicas. Petrópolis: Vozes.

TARDIF, M. - LESSARD, C. - LAHAYE, L Os professores face ao saber. Esboço de uma problemática do saber docente. In: "Teoria \& Educação" (1991)4, 215-233.

TARDIF, M. 1999. Elementos para uma epistemologia da prática profissional dos professores e suas conseqüências em relação à formação para o magistério. Quebec: CRIFPE.

TEIXEIRA, A. 1998. Educação e universidade. Rio de Janeiro: UERJ.

UNESCO. 1998. Declaração Mundial sobre Educação Superior no século XXI: visão e ação. Piracicaba: UNIMEP.

VEIGA, I. (Org.). 1991. Técnicas de ensino: por que não?Campinas: Papirus. VEIGA, I. (Org.). 1997. Didática: o ensino e suas relações. Campinas: Papirus. ZAINKO, M. 1998. Planejamento, universidade e modernidade. Curitiba: All-Graf. 